\title{
Gender Differences in the Association between Circadian Preference and Attachment Style
}

\author{
Seahyun O, Jooyoung Lee, and Seog Ju Kim \\ Department of Psychiatry, Sungkyunkwan University School of Medicine, Samsung Medical Center, Seoul, Korea
}

\begin{abstract}
Objective: The present study aims to explore gender differences in the association between circadian preference and attachment style in a community sample. Methods: A total of 171 community-dwelling adults (98 males and 73 females, mean age $=41.06 \pm 8.21$ years) were recruited. The Morningness-Eveningness Questionnaire (MEQ) was used to measure the circadian preferences, and attachment style was assessed by the Relationship Style Questionnaire (RSQ). The Center for Epidemiological Studies-Depression Scale (CES-D) was used to assess depressive symptoms. The association between circadian preference and attachment style was examined by gender. Results: The MEQ significantly predicted dismissing attachment $(\beta=-0.254, p=0.001)$ and fearful attachment ( $\beta=-0.177, p=0.016)$ after controlling for age, gender, and the CES-D score. The MEQ predicted dismissing attachment $(\beta=-0.372, p=0.002)$ and fearful attachment $(\beta=-0.237, p=0.040)$ in males, but not in females after controlling for age and CES-D score. Conclusion: The current finding suggests an association between circadian preference and attachment style, which differed by gender.
\end{abstract}

Key Words: Circadian preferences; Morningness-eveningness; Attachment style; Gender

Received: December 3, 2020 Revised: December 8, 2020 Accepted: December 8, 2020

Corresponding author: Seog Ju Kim, MD, PhD, Department of Psychiatry, Sungkyunkwan University School of Medicine, Samsung Medical Center, 81 Ilwon-ro, Gangnam-gu, Seoul 06351, Korea.

Tel: 82-2-3410-3583, Fax: 82-2-3410-0050, E-mail: ksj7126@skku.edu

(a) This is an Open Access article distributed under the terms of the Creative Commons Attribution Non-Commercial License (https://creativecommons.org/licenses/by$\mathrm{nc/4.0)}$ which permits unrestricted non-commercial use, distribution, and reproduction in any medium, provided the original work is properly cited.

\section{INTRODUCTION}

The circadian preference, i.e., a preference for morningness (i.e., morning/day activity) or eveningness (i.e., evening/night activity), is an indicator of the circadian rhythm. The circadian preference has been reported to be related to various personality traits [1-3].

Among theories of personality traits, attachment theory posits that caregiving experiences are represented by internal working models (IWMs) [4]. Such IWMs serve as a prototype for future relationships, and influence self-expression and the ability to cope with distressing emotions. Attachment style plays a significant role in understanding how individuals perceive and relate to their world, and could be closely related to an individual's personality traits. Bartholomew and Horowitz [5] described four types of attachment style, as follows: 1) Secure attachment refers to an infant or adult who does not avoid others and does not feel anxious about being abandoned by others; 2) The dismissing attachment style refers to avoidance of others without feeling anxious about abandonment; 3) In preoccupied attachment, the person places great value on interpersonal relationships because of a great fear of being abandoned by others; and 4) The fearful attachment style describes adults and infants with negative models of the self and others, who show both attachment and avoidance behaviors when abandoned.

Many studies have investigated the associations between circadian preference and personality style, among other psychological factors [6,7]. However, no study has revealed a link between attachment style and circadian preference. Moreover, as previous studies have reported that both circadian preference and attachment style differ between the genders [5,8-13], identifying gender differences in any possible relationship is necessary.

Thus, the present study aimed to explore gender differences in the association between morningness-eveningness and attachment style in a community sample. We hypothesized that circadian preference predicts an individual's attachment style. We also hypothesized that there would be a gender difference in the relationship between morningness-eveningness and attachment style. 


\section{METHODS}

\section{Participants}

Initially, 207 participants were recruited by advertisements placed in apartment blocks, churches, universities, and a public health center. Data from 171 participants [ 98 males (47.4\%) and 73 females $(52.6 \%)$, mean age $=41.06 \pm 8.21$ years] were included in the final analysis; 36 participants who did not complete the questionnaire were excluded. No significant difference in age was observed between the males and females. All participants provided informed consent, and this study was approved by the Institutional Review Board of Gachon University of Medicine and Science.

\section{Assessment of morningness and eveningness}

The Korean version of the Morningness-Eveningness Questionnaire (MEQ) was used to measure the preference for morningness or eveningness. The MEQ consists of 19 items, with higher scores suggesting a tendency toward morningness [14]. The MEQ classifies respondents into five categories, but no such categorization was performed in this study.

\section{Assessment of attachment style}

The Korean version [15] of Relationship Style Questionnaire (RSQ) was used to assess the attachment style of the adults. The RSQ measures four different relationship styles based on Bartholomew's model, which describes attachment style via the two dimensions of low/high avoidance and low/high dependence [5]. According to Bartholomew's model, the four attachment styles are: 1) secure (low avoidance and dependence), 2) dismissing (high avoidance and low dependence), 3) preoccupied (low avoidance and high dependence), and 4) fearful (high avoidance and dependence). A higher score on a given subscale indicates that the respondent is better described by it [16]. The RSQ consists of 30 questions, each scored from 0 to 4 points.

\section{Assessment of depression}

The Center for Epidemiological Studies-Depression Scale (CESD) [17] is used to evaluate the severity of depressive symptoms and screens for depressive episodes. The Korean version [18] was used in the present study. This scale consists of 20 items, each scored from 0 to 3 points $[6,19]$.

\section{Statistical analysis}

The independent $\mathrm{t}$-test was used to detect gender differences. Pearson's correlation analysis was conducted to explore the relationships among continuous variables. Regression analysis was used to determine whether there was any association between circadian preference and attachment style after controlling for age, gender, and depression. Three regression models were devised: Model 1 (dependent variable: MEQ score; independent variable: RSQ score), Model 2 (dependent variables: MEQ score, age, and gender; independent variable: RSQ score), and Model 3 (dependent variables: MEQ score, age, gender, and CES-D score; independent variable: RSQ score). The analyses were repeated for each gender. All analyses were conducted with SPSS 22.0 software (IBM Corp., Armonk, NY, USA).

\section{RESULTS}

The circadian preference and attachment style of all participants are described in Table 1 . The MEQ score was significantly higher in females than males $(t=2.458, p=0.015)$. Among the four attachment styles, the preoccupied attachment score was significantly higher in male than female participants $(\mathrm{t}=-2.533, \mathrm{p}=0.012)$. The MEQ score was positively correlated with age $(r=0.223, p=$ $0.003)$. The MEQ score was significantly correlated with higher dismissing attachment $(\mathrm{r}=-0.226, \mathrm{p}=0.003)$ and fearful attachment $(\mathrm{r}=0.159, \mathrm{p}=0.038)$. The CES-D score was significantly correlated with higher preoccupied attachment $(\mathrm{r}=0.223, \mathrm{p}=0.003)$ and fearful attachment $(\mathrm{r}=0.397, \mathrm{p}<0.001)$.

The multiple regression analysis indicated an independent association between the RSQ and MEQ scores (Table 2). In Model 1 , the MEQ score significantly predicted dismissing attachment $(\beta=-0.226, p=0.003)$ and fearful attachment $(\beta=-0.159, p=0.038)$. In Model 2, the associations of the MEQ score with dismissing attachment $(\beta=-0.257, p=0.001)$ and fearful attachment $(\beta=-0.186$, $\mathrm{p}=0.019$ ) remained significant after controlling for age and gender. In Model 3, the associations of the MEQ score with dismissing attachment $(\beta=-0.254, p=0.001)$ and fearful attachment $(\beta=$

Table 1. Differences in circadian preference and attachment style between males and females

\begin{tabular}{|c|c|c|c|c|c|}
\hline & Total $(n=171)$ & Male (n=98) & Female $(n=73)$ & $\mathrm{t}$ & $\mathrm{p}$ \\
\hline Age (yr) & $41.06 \pm 8.21$ & $40.03 \pm 8.70$ & $41.84 \pm 7.78$ & 1.430 & 0.154 \\
\hline MEQ score & $50.40 \pm 7.79$ & $48.73 \pm 8.91$ & $51.64 \pm 6.61$ & 2.458 & $0.015^{*}$ \\
\hline \multicolumn{6}{|l|}{ RSQ score } \\
\hline Secure attachment & $17.34 \pm 2.40$ & $16.95 \pm 2.54$ & $17.63 \pm 2.25$ & 1.869 & 0.063 \\
\hline Dismissing attachment & $14.44 \pm 2.64$ & $14.59 \pm 2.56$ & $14.33 \pm 2.70$ & -0.642 & 0.522 \\
\hline Preoccupied attachment & $11.59 \pm 1.92$ & $12.01 \pm 1.78$ & $11.28 \pm 1.96$ & -2.533 & $0.012^{*}$ \\
\hline Fearful attachment & $10.86 \pm 2.54$ & $11.03 \pm 2.70$ & $10.73 \pm 2.42$ & -0.744 & 0.458 \\
\hline CES-D score & $11.68 \pm 9.24$ & $11.22 \pm 8.43$ & $12.03 \pm 9.83$ & 0.567 & 0.572 \\
\hline
\end{tabular}

${ }^{*} \mathrm{p}<0.05$. MEQ: Morningness-Eveningness Questionnaire, RSQ: Relationship Style Questionnaire, CES-D: Center for Epidemiological StudiesDepression Scale 
$-0.177, \mathrm{p}=0.016)$ were significant after controlling for age, gender, and the CES-D score.

The results of the multiple regression analyses conducted separately for each gender are presented in Table 3. Significant associations between the MEQ and RSQ scores were found only in the male group. The MEQ score significantly predicted dismissing attachment (Model 1, $\beta=-0.340, p=0.003$ ) in males, even after controlling for age (Model 2: $\beta=-0.375, p=0.002$ ), and for age and the CES-D score (Model 3: $\beta=-0.372, p=0.002$ ). In addition, the MEQ score significantly predicted fearful attachment after controlling for age and depression (Model 3) $(\beta=-0.237, \mathrm{p}=0.040)$.

\section{DISCUSSION}

The present study was aimed to test for an association between circadian preference and attachment style. Consistent with our first hypothesis, circadian preference predicted attachment style, independent of age, gender, and depression status. Consistent with our second hypothesis, a gender difference was detected in the association between circadian preference and attachment style. An independent association between eveningness and higher dismissing and fearful attachment was only seen in males, and persisted after controlling for age and depression.

The current findings indicate that the circadian preference may have psychological effects, including attachment style. Previous studies have reported significant associations between circadian preference and psychological factors [7]. However, this is the first study to investigate the association between circadian preference and attachment style.
Previous studies have reported gender differences in circadian preference [20] and attachment style [21]. The current study also showed higher morningness and a preoccupied attachment style in males, which supported the gender differences in circadian preference and attachment style.

The present study also showed that dismissing attachment was highly associated with eveningness, even after controlling for gender, age, and depression, suggesting that those with higher eveningness tend to have dismissing attachment regardless of their demographic characteristics or mood. The key traits of dismissing attachment are a lack of interpersonal relationships and emotional indifference [6], and those with the eveningness preference may wish to avoid close relationships during the daytime, instead preferring to be alone during the night.

Fearful attachment was also independently related to eveningness. Individuals with fearful attachment tend to show unpredictable behavior in interpersonal relationships and their judgment criteria are not related to interpersonal relationships [3]. Eveningness is more strongly related to an unstable circadian rhythm and lifestyle compared to morningness [22]. Therefore, unstable traits, such as a fearful attachment style, may be linked to the circadian instability of eveningness.

Additionally, separate analyses by gender showed that the association between circadian preference and dismissing/fearful attachment was present only in males. This gender difference may be related to the higher morningness of females. In addition, females with the eveningness preference may not avoid interpersonal relationships during the daytime or have an unstable life rhythm, as seen in males with the eveningness preference.

Table 2. Association between attachment style and circadian preferences in the entire cohort

\begin{tabular}{|c|c|c|c|c|}
\hline & Secure attachment & Dismissing attachment & Preoccupied attachment & Fearful attachment \\
\hline \multirow[t]{2}{*}{ Model 1} & $\beta=0.135$ & $\beta=-0.226^{*}$ & $\beta=-0.033$ & $\beta=-0.159^{*}$ \\
\hline & $\mathrm{p}=0.078$ & $\mathrm{p}=0.003$ & $\mathrm{p}=0.666$ & $\mathrm{p}=0.038$ \\
\hline \multirow[t]{2}{*}{ Model 2} & $\beta=0.136$ & $\beta=-0.257^{\dagger}$ & $\beta=0.016$ & $\beta=-0.186^{*}$ \\
\hline & $\mathrm{p}=0.085$ & $\mathrm{p}=0.001$ & $\mathrm{p}=0.842$ & $\mathrm{p}=0.019$ \\
\hline \multirow[t]{2}{*}{ Model 3} & $\beta=0.134$ & $\beta=-0.254^{\dagger}$ & $\beta=0.021$ & $\beta=-0.177^{*}$ \\
\hline & $\mathrm{p}=0.090$ & $\mathrm{p}=0.001$ & $\mathrm{p}=0.781$ & $\mathrm{p}=0.016$ \\
\hline
\end{tabular}

${ }^{*} \mathrm{p}<0.05,{ }^{\dagger} \mathrm{p}<0.01$. Model 1 -Dependent variable: MEQ score; independent variable: attachment score. Model 2-Dependent variables: MEQ score, age, and gender; independent variable: attachment score. Model 3-Dependent variables: MEQ score, age, gender, and CES-D score; independent variable: attachment score. MEQ: Morningness-Eveningness Questionnaire, CES-D: Center for Epidemiological Studies-Depression Scale

Table 3. Association between attachment style and circadian preference by gender

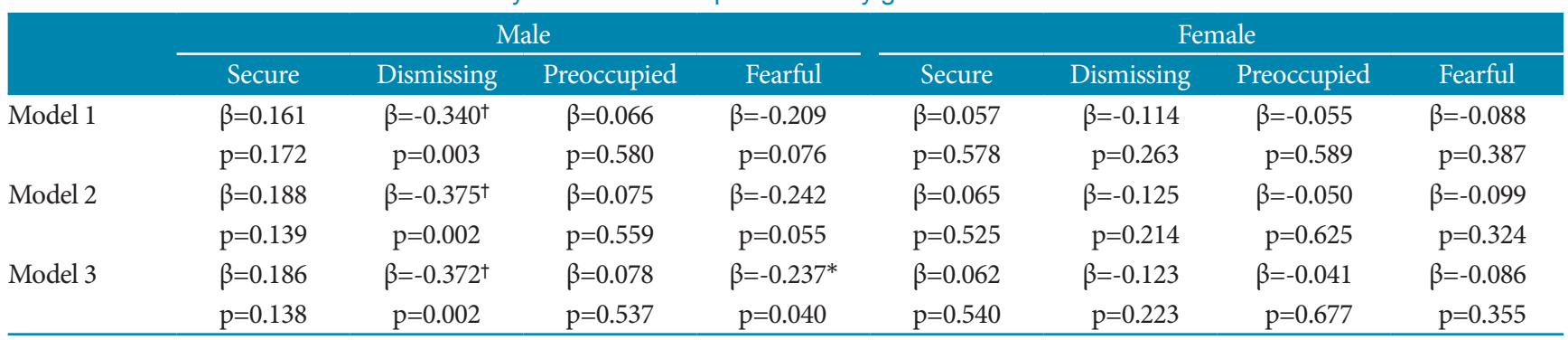

${ }^{*} \mathrm{p}<0.05,{ }^{\dagger} \mathrm{p}<0.01$. Model 1 -Dependent variable: MEQ score; independent variable: attachment score. Model 2-Dependent variables: MEQ score, and age; independent variable: attachment score. Model 3-Dependent variables: MEQ score, age, and CES-D score; independent variable: attachment score. MEQ: Morningness-Eveningness Questionnaire, CES-D: Center for Epidemiological Studies-Depression Scale 
Several limitations of this study should also be discussed. First, measuring circadian preference, attachment style, and depression through self-report questionnaires might not fully reflect the characteristics of the individual. Second, the sample size was not sufficiently large to represent the entire population. A future study should include a larger and more diverse sample with respect to age. Finally, the circadian preference does not completely represent biological circadian rhythms in the absence of measurement of biological markers of circadian rhythms, such as melatonin or cortisol.

In conclusion, in the present study circadian preference was independently associated with a specific attachment style. Moreover, there were gender differences in the association between circadian preference and attachment style.

\section{Acknowledgments}

This research was supported by the Brain Research Program through the National Research Foundation of Korea (NRF) funded by the Korean govoerment (MSIT) (No. 2016M3C7A1904338), National Research Foundation of Korea (NRF) grant funded by the Korean government (MSIT) (No. 2020R1F1A1049200), and the Bio \& Medical Technology Development Program of the National Research Foundation (NRF) funded by the Korean government (MSIT) (No. 2020M3E5D908056111).

\section{Conflicts of Interest}

The authors have no potential conflicts of interest to disclose.

\section{Author Contributions}

Conceptualization: Seog Ju Kim. Data curation: Seog Ju Kim, Jooyoung Lee, Seahyun O. Formal analysis: Seog Ju Kim, Jooyoung Lee, Seahyun O. Funding acquisition: Seog Ju Kim. Investigation: Seog Ju Kim, Seahyun O. Methodology: Seog Ju Kim, Jooyoung Lee, Seahyun O. Project administration: Seog Ju Kim. Resources: Seog Ju Kim. Software: Seog Ju Kim, Jooyoung Lee. Supervision: Seog Ju Kim. Validation: Jooyoung Lee, Seahyun O. Visualization: Seahyun O. Writing-original draft: Seahyun O. Writingreview \& editing: Seog Ju Kim, Jooyoung Lee.

\section{ORCID iDs}

Seahyun O (D)

https://orcid.org/0000-0003-0990-8974

Jooyoung Lee (D)

https://orcid.org/0000-0002-8774-7128

Seog Ju Kim (B)

https://orcid.org/0000-0003-2467-5451

\section{REFERENCES}

1. Adan A, Lachica J, Caci H, Natale V. Circadian typology and temperament and character personality dimensions. Chronobiol Int 2010;27:181-193.

2. Ong JC, Huang JS, Kuo TF, Manber R. Characteristics of insomniacs with self-reported morning and evening chronotypes. J Clin Sleep Med 2007;3: 289-294.

3. Yeo KE, Kim SJ. Adult attachment styles and alexithymia. Bull Yong-In Psychiatr Inst 2014;20:3-12.

4. Bowlby J. Attachment and loss. Vol. 3, Loss: sadness and depression. New York: Basic Books; 1980.

5. Bartholomew K, Horowitz LM. Attachment styles among young adults: a test of a four-category model. J Pers Soc Psychol 1991;61:226-244.

6. Kim SJ, Cho SJ, Jang HM, Shin J, Park PW, Lee YJ, et al. Interaction between brain-derived neurotrophic factor Val66Met polymorphism and recent negative stressor in harm avoidance. Neuropsychobiology 2010;61:19-26.

7. Ham BJ, Kim L. Insomnia and personality trait. Sleep Med Psychophysiol 2002;9:100-105.

8. Baehr EK, Revelle W, Eastman CI. Individual differences in the phase and amplitude of the human circadian temperature rhythm: with an emphasis on morningness-eveningness. J Sleep Res 2000;9:117-127.

9. Moe KE, Prinz PN, Vitiello MV, Marks AL, Larsen LH. Healthy elderly women and men have different entrained circadian temperature rhythms. J Am Geriatr Soc 1991;39:383-387.

10. Ridge SR, Feeney JA. Relationship history and relationship attitudes in gay males and lesbians: attachment style and gender differences. Aust N Z J Psychiatry 1998;32:848-859.

11. Schmitt DP. Are men universally more dismissing than women? Gender differences in romantic attachment across 62 cultural regions. Pers Relatsh 2003; 10:307-331.

12. Wendt HW. Population, sex and constitution in typologies based on individual circadian rhythms. Biol Rhythm Res 1977;8:286-290.

13. Wilson GD. Personality, time of day and arousal. Pers Individ Differ 1990;11: 153-168.

14. Yu NJ, Shin SC, Wang SK. A study on the standardization of the Korean version of JA Horne and O. Ostbergs' Morningness-Eveningness Questionnaire and on the sleep pattern. J Korean Neuropsychiatr Assoc 1995;34:642.

15. Lee JH. The effects of attachment, social anxiety and coping styles on eating behaviors for college female students [master's thesis]. Seoul: Yonsei University Seoul; 2006.

16. Griffin DW, Bartholomew K. Models of the self and other: fundamental dimensions underlying measures of adult attachment. J Pers Soc Psychol 1994; 67:430.

17. Radloff LS. The CES-D scale: a self-report depression scale for research in the general population. Appl Psychol Meas 1977;1:385-401.

18. Cho MJ, Kim KH. Diagnostic validity of the CES-D (Korean version) in the assessment of DSM-III-R major depression. J Korean Neuropsychiatr Assoc 1993;32:381-399.

19. Myers JK, Weissman MM. Use of a self-report symptom scale to detect depression in a community sample. Am J Psychiatry 1980;137:1081-1084.

20. Randler C. Gender differences in morningness-eveningness assessed by selfreport questionnaires: a meta-analysis. Pers Individ Differ 2007;43:16671675.

21. Joo EJ. Parent, peer, and romantic attachment of adolescents according to gender and age differences. Korean J Youth Stud 2011;18:141-171.

22. Hess B, Sherman MF, Goodman M. Eveningness predicts academic procrastination: the mediating role of neuroticism. J Soc Behav Pers 2000; $15: 61$. 